\title{
The asphalt pavement structure mechanics response under the variable speed moving load
}

\author{
JIAN HONG GAO \\ Architecture and Civil Engineering School,UST Inner Mongolia,Baotou 014010,China \\ gjh76219@163.com
}

\begin{abstract}
KEYWORD: Variable speed, Moving load, Asphalt Pavement Structure, Mechanics response ABSTRACT: Aiming at the common asphalt pavement structure combination, large general finite element software is used to build the three-dimensional model based on the multi-layer elastic system theory. The pavement structure vertical displacement and stress are analyzed entirely under the moving load. The results show: The faster the load speed, the fluctuation displacement and maximum displacement in pavement structure layer is smaller. The load moving speed has little effect to the maximum vertical stress of the structure layer, but the greater the speed, the subsequent stress fluctuating is more furiously. In the same speed, each node equivalent stress and time relationship curve is very similar, and the change rule almost identical. The above shows the influence of dynamic load on the pavement structure layer can not be ignored.
\end{abstract}

\section{Introduction}

The vehicle axis load on the road is heavier and the channel transportation characteristic is clearer along with the road transport capability promotion continually. So the road structure layers always appear early part damage: such as push motion, crack, rut etc early damages. One side, the causes of these damages is affected by environmental factors. On the other hand is affected by the traffic load. The load static pressure will affect the service life of the road; the car's dynamics will also cause serious diseases on pavement. At present the city road and highway design in China are all based on elastic layered system under the static load model, and the actual wheel loads are dynamic, the road bearing the vertical vibration and shock \& horizontal effect along with time changing. As the pavement structure itself is sensitive to load time, so the mechanics properties caused from the dynamic load are different greatly from the static model. Using finite element software to building the asphalt pavement dynamic load three-dimensional entity model [3-4], the pavement mechanics response is calculated, and the structure layer stress and displacement under the dynamic load are discussed. So some useful laws can be given and referenced.

\section{Moving load}

The moving load belongs to the dynamics field. Different from the static analysis, dynamic analysis must consider the load change with time and its influence on the damping and inertia. According to structure bearing the load type, dynamic analysis can be roughly divided into the following types: Modal analysis, Spectral analysis, Random vibration analysis and the transient dynamic analysis. The transient dynamic analysis is mainly used for analysis of structure response of load changes with time; ensure that the structure does not appear to damage under impact load. The pavement structure layer mechanical response analysis of moving load is a transient dynamics time course analysis in this paper.

\section{The finite element model building and interrelated parameters selection}

\section{ANSYS model.}

The paper chooses multy-layer pavement structure and supposes the material is linear \& elastomeric, shown as chart1. The building model cell is three-dimensional hexahedron 8-node and the model size $(X, Y 、 Z)$ is $3.0 \mathrm{~m} \times 2.0 \mathrm{~m} \times 2.0 \mathrm{~m}$. The boundary: underside $U Y=0$; driving directions is $X$ direction, and from beginning to end $U X=0 ; Z$ direction is the road width and no restriction. The contact condition is entirety continuum. The load is BZZ-100, that is to say the axis heft 100 $\mathrm{kN}$, the wheel pressure $0.7 \mathrm{Mpa}$. This paper uses international units. 


\section{Moving load parameters.}

In this paper, the transient analysis uses FULL method. The design speed V=20km/h and $60 \mathrm{~km} / \mathrm{h}$. In order to save the computer running time and get enough precision, model grid division is dense close to the pavement structure layer, and is sparse near the road bottom. The scalar parameters are pre defined in order to using the software program design language APDL for programming to realize repeated load. Mainly these parameters include the element unit length in the load moving direction, load velocity, the magnitude of load and passing time by each element.

The program will eventually transform the initial load into nodes load, and become a concentrated load no matter its adding form in the finite element method. So this paper program imposed concentrated load directly to the nodes. According to the international system of units the load should be N, standard axle load should be $100000 \mathrm{~N}$. The concentrated load moves from the first node to the last node with a constant velocity through programming *do and *enddo cycle statement. The load is deleted after the end of each load step, and then it is applied to the next node to solve, in turn forward until the end. Each load step was divided into 5 load step. The model adopts the typical semi rigid pavement structure; specific data are shown in table 1.

Table 1 pavement structure combination

\begin{tabular}{|c|c|c|c|}
\hline combination & $\begin{array}{c}\text { Modulus and } \\
\text { thickness }\end{array}$ & $\begin{array}{c}\text { Poisson } \\
\text { ratio }\end{array}$ & density \\
\hline $\begin{array}{c}\text { Asphalt concrete } \\
\text { surface layer }\end{array}$ & $\begin{array}{c}\mathrm{E} 1=1200 \mathrm{Mpa} \\
\mathrm{h} 1=27 \mathrm{~cm}\end{array}$ & 0.35 & $2400 \mathrm{~kg} / \mathrm{m}^{3}$ \\
\hline $\begin{array}{c}\text { Semi-rigid } \\
\text { layer }\end{array}$ & $\begin{array}{c}\mathrm{E} 2=1300 \mathrm{Mpa} \\
\mathrm{h} 2=48 \mathrm{~cm}\end{array}$ & 0.2 & $2400 \mathrm{~kg} / \mathrm{m}^{3}$ \\
\hline groundwork & $\begin{array}{c}\mathrm{E} 0=40 \mathrm{Mpa} \\
\mathrm{h} 3>200 \mathrm{~cm}\end{array}$ & 0.4 & $1800 \mathrm{~kg} / \mathrm{m}^{3}$ \\
\hline
\end{tabular}

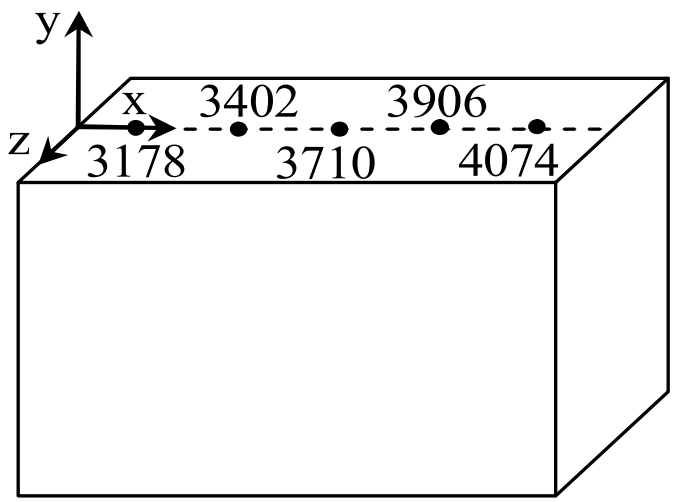

Figure. 1 load moving direction and passing nodes

\section{The asphalt pavement dynamic response analysis under a variable velocity moving load}

The node vertical displacement and stress change regulations with time under a variable velocity moving load.

The model has 43 units in the load moving direction, counting the boundary point all has 44 nodes. According to the moving speed $20 \mathrm{~km} / \mathrm{h}$ and $60 \mathrm{~km} / \mathrm{h}$ computing, load action time total is $0.54 \mathrm{~s}$ and $0.18 \mathrm{~s}$. The finite element program used in this article provision: stress in tension is positive, stress in compression is negative.

Figure 1 is the load moving direction and passing node diagram, and 5 representative nodes are chosen in the load moving track. Figure 2 shows the curves of vertical displacement with time of the two middle nodes of the Fig.1. Reference to Figure 2 (a), (c), the vertical displacement of node 3402 fluctuates within $0.0004 \sim-0.0012 \mathrm{~m}$ and the vertical displacement of node 3710 fluctuates within $0.0004 \sim-0.0012 \mathrm{~m}$, when the load moving speed is slow, and the vibration frequency is smaller, but the amplitude of fluctuations is larger. The vertical displacement increases to $-0.0027 \mathrm{~m}$ 
or $-0.0025 \mathrm{~m}$ instantaneously when the load is moved to node 3402 or 3710 . After the load is removed, the nodes 3402 or 3710 maintain the original frequency and amplitude of fluctuation. Reference to Figure 2 (b), (d), the vertical displacement of node 3402 and 3710 fluctuates within 0 scale mark when the load moving speed is relatively fast, and the vibration frequency is larger, but the amplitude of fluctuations is smaller. The vertical displacement all increases to $-0.0022 \mathrm{~m}$ instantaneously when the load is moved to node 3402 or 3710 . After the load is removed, the nodes 3402 or 3710 maintain the original frequency and amplitude of fluctuation.

Thus, the faster the load moving speeds, the smaller the fluctuation displacement and maximum displacement in pavement structure. From another point of view, we can think of pavement layer strength and rigidity are increased, and it is in the interest of the road.

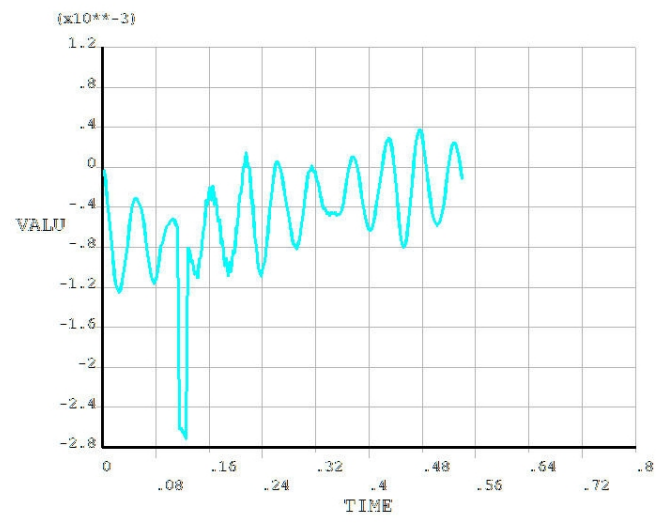

(a) $\mathrm{v}=20 \mathrm{~km} / \mathrm{h} \quad($ node3402)

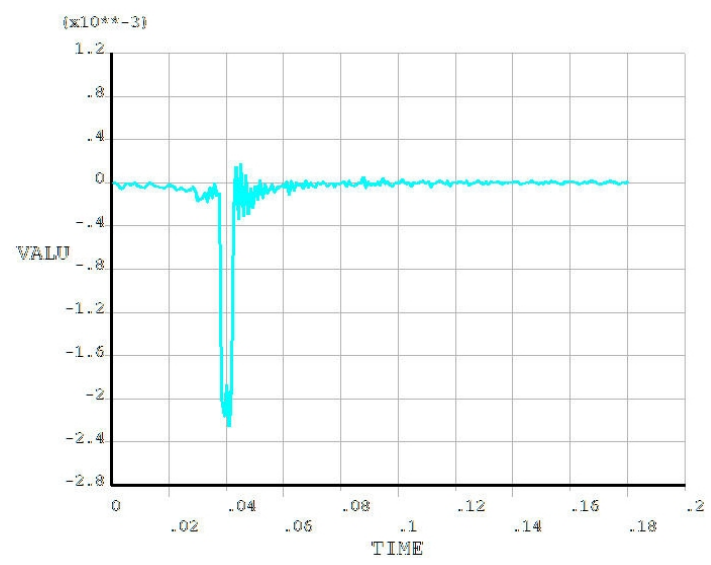

(b) $\mathrm{v}=60 \mathrm{~km} / \mathrm{h} \quad($ node 3402$)$

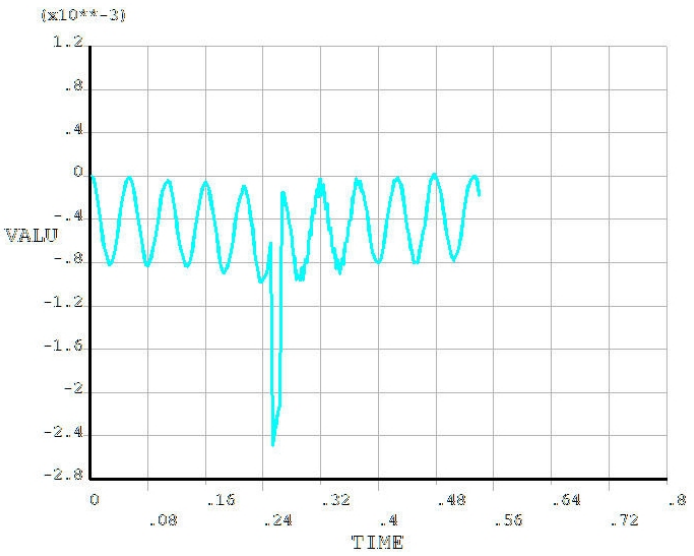

(c) $\mathrm{v}=20 \mathrm{~km} / \mathrm{h} \quad($ node 3710$)$ 


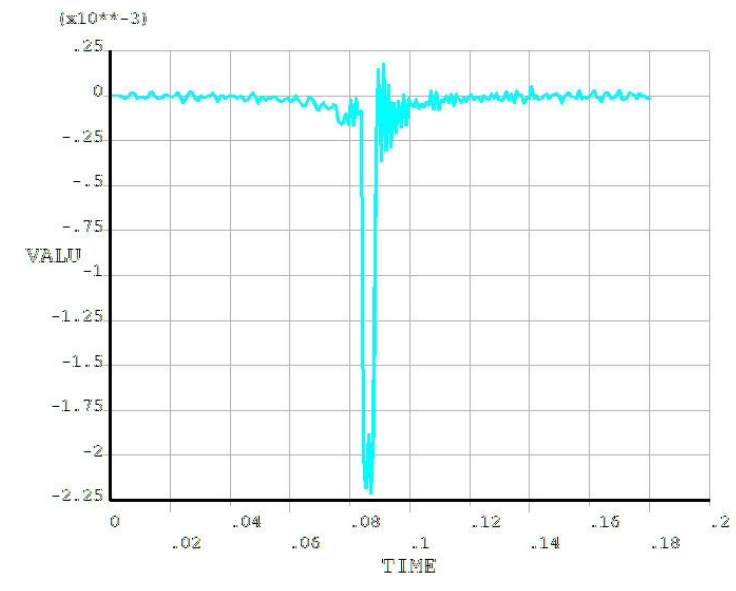

$(\mathrm{d}) \mathrm{v}=60 \mathrm{~km} / \mathrm{h} \quad($ node 3710$)$

Figure 2 the curves of two nodes vertical displacement with time

Figure 3 shows the curves of vertical stress with time of the two middle nodes of the Fig.1. Reference to Figure 3 (a), (c) the vertical stress of node 3402 and 3710 is almost zero when the load moving speed is slow and the load moving range before in node 3402 or 3710 . The vertical stress all increases to about $-43 \mathrm{MPa}$ instantaneously when the load is moved to node 3402 or 3710 , and both sides of load point have uplift. After the load is removed, the nodes frequency and amplitude of fluctuation decrease gradually along with the time extends. Reference to Figure 3 (b), (d), the vertical stress of node 3402 and 3710 fluctuates along 0 tick mark up and down when the load moving speed is fast and the load moving range before in node 3402 or 3710 . The vertical stress all increases to about $-43 \mathrm{MPa}$ instantaneously when the load is moved to node 3402 or 3710 , and both sides of load point have uplift. After the load is removed, the nodes frequency and amplitude of fluctuation are bigger than Fig.3 (a), (c) and then decrease gradually along with the time extends. Thus, the load moving speed has little effect to the structure layer vertical stress, but the greater the load moving speed, the more intense the subsequent vibration.

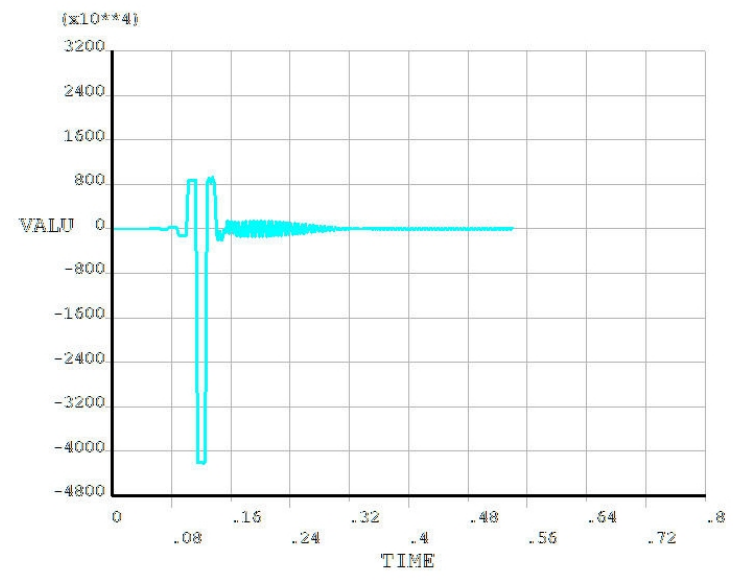

(a) $\mathrm{v}=20 \mathrm{~km} / \mathrm{h} \quad($ node 3402$)$ 


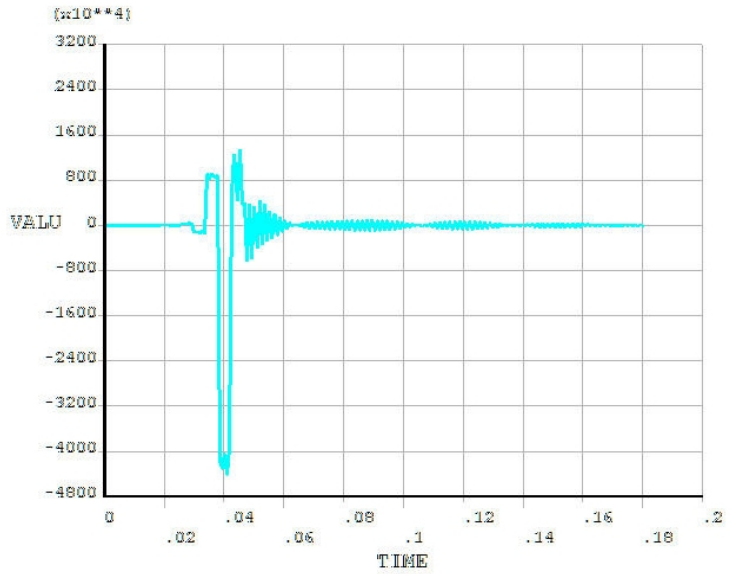

(b) $\mathrm{v}=60 \mathrm{~km} / \mathrm{h} \quad($ node 3402$)$

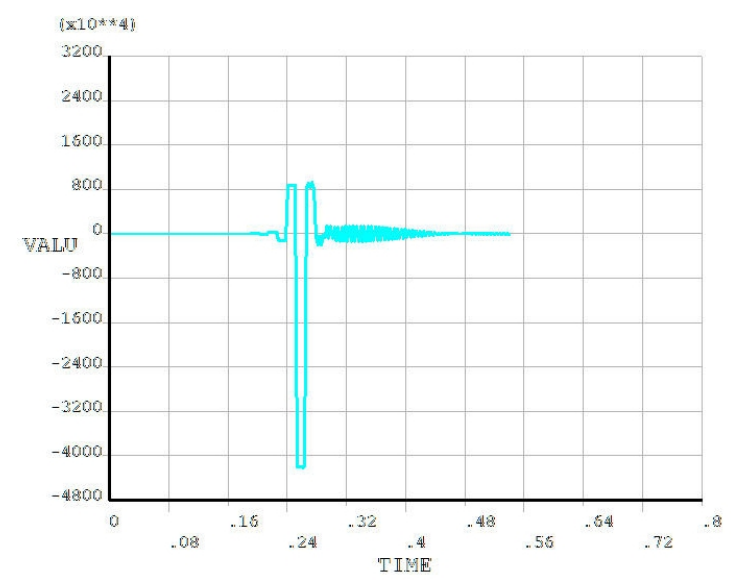

(c) $\mathrm{v}=20 \mathrm{~km} / \mathrm{h} \quad($ node 3710$)$

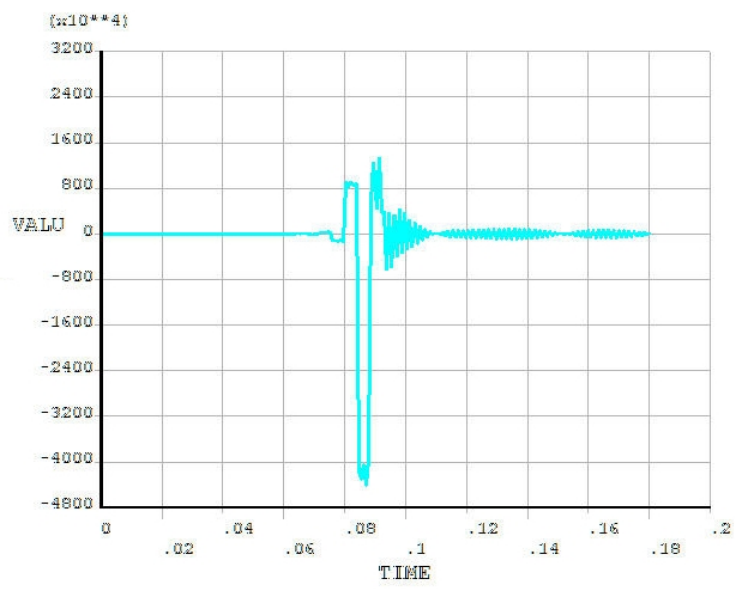

(d) $\mathrm{v}=60 \mathrm{~km} / \mathrm{h} \quad($ node 3710$)$

Figure 3 the curves of two nodes vertical stress with time 
The change laws of node von mises equivalent stress with time in the same load moving speed.

Figure 4 shows the curves of the von mises equivalent stress with time of the node 3402 and 4074 in the Fig.1. Reference to Fig.4, the two nodes equivalent stress curve is very similar and its change laws: the von mises equivalent stress fluctuates along 0 tick mark up and down before the moving load reaches the node 3402 and 4074. The von mises equivalent stress increases to the same maximum numerical value instantaneously when the load is moved to node 3402 and 4074 . After the load is removed, the node 3402 and 4074 frequency and amplitude of fluctuation are bigger slightly than origin time and then decrease gradually along with the time extends.

Comparing Fig.3 and Fig.4, the relationship curves of the node vertical stress, von mises equivalent stress with time is very different. Each has a particular emphasis and study value.

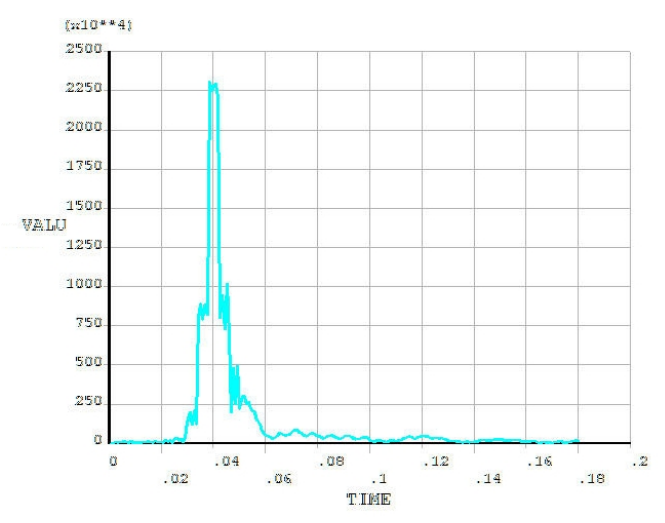

(a) node 3402 von mises equivalent stress

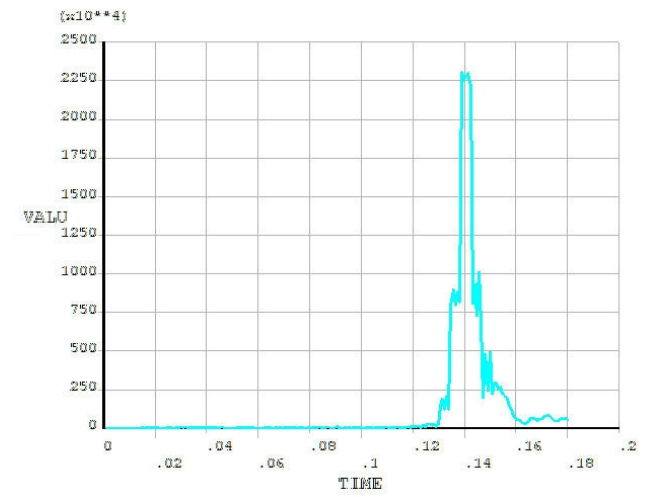

(b) node 4074 von mises equivalent stress

Figure. 4 the curves of node von mises equivalent stress with time( $V=60 \mathrm{~km} / \mathrm{h})$

\section{Conclusions}

The faster the load speed, the fluctuation displacement and maximum displacement in pavement structure layer is smaller. The load moving speed has little effect to the maximum vertical stress of the structure layer, but the greater the speed, the subsequent stress fluctuating is more furiously.

In the same speed, each node equivalent stress and time relationship curve is very similar, and the change rule almost identical.

In summary, the dynamic load is different greatly from the static load to the pavement structure mechanical response, and the influence can not be ignored.

\section{References}

[1] Ben-guo He. ANSYS civil engineering application examples [M]. Beijing: China water resources and hydropower publishing company, 2011.

[2] China calling criterion. Criterion for design of road asphalt concrete pavement. (JTG D50-2006).Beijing: people traffic publishing company, 2006

[3] Xu-cheng Wang, Min Shao. The finite element fundamental principle and numerical value 
method [M]. Beijing: Tsinghua University publishing company, 1997.

[4] Xue-jun Deng. Roadbed and road surface engineering [M]. Beijing: people traffic publishing company, 2008.100-120 